\title{
Optimization of Processing Parameters of Red Gypsum-Based Brick Manufacturing using Response Surface Methodology
}

\author{
Mohd Amirul Hakim Sidek ${ }_{2}^{\mathrm{a}}$ Rosli M. Yunus ${ }^{\mathrm{a}}$, Mohammad Al-Nizar Khan Ahmad Khan ${ }^{\mathrm{a}}$, Muhammad \\ Remanul Islam ${ }^{\mathrm{b}^{*}}$ \\ ${ }^{a}$ Faculty of Chemical Engineering \& Natural Resources, Universiti Malaysia Pahang \\ Gambang, Pahang, Malaysia \\ ${ }^{\mathrm{b}}$ Section of Chemical Engineering Technology, Malaysian Institute of Chemical and Bioengineering Technology, University of \\ Kualalumpur \\ Alor Gajah, Melaka, Malaysia.
}

${ }^{*}$ Corresponding author's email: muhammad.remanul [AT] unikl.edu.my

\begin{abstract}
The red gypsum (RG) is a waste, industrial by product, can be potentially used for brick manufacturing. In the current study, the manufacturing of bricks using $R G$, sand and cement was optimized using response surface methodology (RSM). The water/cement (w/c) ratio and sand replacement were varied for an optimum compressive strength and water absorption properties of the cement. From the analysis, the average compressive strength of conventional cement brick (CCB) tested was 10.9 MPa. Based on the optimum solution from the RSM analysis, possible cost prediction was estimated which can provide some valuable information to the manufacturer.
\end{abstract}

Keywords--- Red gypsum (RG); response surface methodology (RSM), brick manufacturing; compressive strength; water absorption.

\section{INTRODUCTION}

The red gypsum is a potential waste based by-products from the titanium industries. The red gypsum (RG) generally consists of approximately $70 \% \mathrm{CaSO}_{4} \cdot 2 \mathrm{H}_{2} \mathrm{O}$ and $28 \%$ iron oxide $\left(\mathrm{Fe}_{2} \mathrm{O}_{3}\right)$ [1]. This is the main reason why RG does not seem to possess sufficient heat during hydration process which is needed to form bonds when mixed with water. The application of RG is therefore mainly made possible by treating it with chemicals or by using it with other organic solvents where it may act as a polymer. Reports on the physical characteristic of RG are basically limited in literature. This result classifies RG as Clay under AASTHO classification of soil. This also reflects the behaviour of RG as non-cohesive material. To further illustrate this behaviour, the particle size distribution of RG has been explained using MASTERSIZER 2000 and the particle size pattern.

Based on previous reports, it was concluded that $90 \%$ of RG sample is finer than $60 \mu \mathrm{m}$ which is similar to the waste used as raw material in cement production [2-3]. Hence, it led to suggestion that RG is rather suitable as filler for compounding materials. On the other hand, RG does not possess pozzolanic characteristics. Therefore, it does not act as binder for the production of secondary hydration reaction. This is mainly caused by the presence of high iron concentration in the particles. Studies by previous researchers have suggested that the presence of metal oxides in materials would create a layer of coating when they are mixed with water and other binders such as cement. Hence the idea of compounding RG with cement of alkali nature would speed up the creation of the coating layer. This would thereby hinder the bond formation during the hydration process. The matrix binding structure would not take place properly, thus presenting negative influence on the strength and other important performance features.

In another vein, RG is a gypsum-based material which is known to be a good water absorbing and high-water retention material [4]. Therefore, RG tends to absorb and retain more water compared to sand. Hence, it can be assumed that the water retained in RG could affect the degree of porosity when it is incorporated into another compound. In addition, mortar and concrete into which RG has been added tends to suffer from low compressive strength when cured in water condition. Generally, based on observations from these authors, it can be concluded that the addition or replacement of material by RG is not suitable for water curing condition due its water absorption and retention ability. From his experiment, it was observed that the water desorption of RG could reach as high as $50 \%$ and a good soil drying suction capacity of about 22.5MPa [5-6]. Thus, the ability of RG to absorb large amount water is the main reason why it could not provide sufficient moisture for hydration reaction to take place [7].

Response surface method (RSM) is a useful technique to optimize processing parameters or a number of factors for a particular response or impact [8-9]. This technique reduces the experimental runs to a minimal value which allows 
the investigators to find an optimum solution. In this current study, the RSM was used successfully for different percentage of water/cement ratio for the compressive strength and water absorption properties of the formulated bricks.

\section{EXPERIMENTAL}

\section{Materials}

The red gypsum was obtained from a company located at Kemaman, Terengganu. The supplier of this waste, Huntsman Tioxide, had already dried and packed the RG in one tonne bags before it is being transported to Pekan, Pahang. However, for the experimental purpose, the RG was further sun-dried and sieved to maximum grain size around $4.75 \mathrm{~mm}$ to its use in the casting process. Ordinary Portland cement (OPC) from Lafarge Malaysia Berhad was used in this study. This material was manufactured in meeting the requirement of Malaysian Standard MS 522: Part 1: 1989 Specification for Ordinary Portland Cement. In this study, sand was used as the fine aggregate and it was obtained from Sungai Pahang. The sand sample was sun-dried and sieved with maximum grain size around $4.75 \mathrm{~mm}$.

\section{Response surface methodology for the optimization}

In this section, an optimization of RG bricks is done by considering two important parameters which are sand replacement percentage and w/c ratio. The experimental design and optimized regression was expected to be developed using Design-Expert (version 7.0 which is based on central composite design (CCD), one of response surface methodology. As stated, the concerns variables for this study are sand replacement percentage (x1) and w/c ratio (x2), both of this variables were used in CCD.

In $\mathrm{CCD}$, there are 5 important levels need to be considered. The level consists of plus and minus one (axial points), centre point and plus and minus one (factorial points). A value of 2 is set for axial design points $(\alpha)$ for this particular design of CCD. In optimizing this mix composition, the variables range of sand replacement is set between $0 \%-100 \%$ and 0.35 to 0.45 for w/c ratio. Table 1 shows the detail value of real value of coded levels.

Table 1. Real values of coded levels

\begin{tabular}{ccccccc}
\hline Variables & Unit & \multicolumn{5}{c}{ Real values of coded levels } \\
\cline { 3 - 7 } & & $-\boldsymbol{\alpha}$ & $\mathbf{- 1}$ & $\mathbf{0}$ & $\mathbf{+ 1}$ & $+\boldsymbol{\alpha}$ \\
\hline Sand replacement & $\%$ & 0 & 25 & 50 & 75 & 100 \\
w/c ratio & & 0.35 & 0.40 & 0.45 & 0.50 & 0.55 \\
\hline
\end{tabular}

The design parameters and value has been set before the analyzation of the parameter is done in Design expert software. Based on all of the parameters and values, 13 sets of experiments where all experiments is runs based on the values given in Table 2

Table 2. Design of experiments for optimization process

\begin{tabular}{ccc}
\hline Run & Sand Replacement $(\%)$ & w/c ratio \\
\hline 1 & 50 & 0.45 \\
2 & 25 & 0.40 \\
3 & 50 & 0.45 \\
4 & 75 & 0.40 \\
5 & 50 & 0.45 \\
6 & 50 & 0.45 \\
7 & 75 & 0.50 \\
8 & 100 & 0.45 \\
9 & 50 & 0.45 \\
10 & 50 & 0.35 \\
11 & 0 & 0.45 \\
12 & 25 & 0.50 \\
13 & 50 & 0.55 \\
\hline
\end{tabular}

\section{RESULTS AND DISCUSSIONS}

\section{Optimization of using response surface method}

In this study, the optimization of bricks was done using a response surface method known as central composite design (CCD). From fit summary of design of experiment, a linear model was suggested to be run for ANOVA test. Table 3 shows analysis of variance table results for this study. From Table 3, it can be seen that the F value is 8.33 which implies that the model is significant. Besides, the model terms are also significant as the "Prob $>\mathrm{F}$ is less than 0.0500. Besides, 
value of "Lack of Fit F-value" of 196.98 indicates that the Lack of Fit is significant. However, a large of noise due to mistakes where it stated from the design that a $0.01 \%$ chance of "Lack of Fit F-value" is obtained. The high values from lack of fit result in lower value of R-squared and Adj R-Squared. Both values of R-squared and Adj R-squared is calculated at only 0.6250 and 0.5500 which indicated that a lots of problems from the generated data. The reduction of $\mathrm{R}-$ squared and Adj R-squared can be seen in Diagnostic Case Statistics where high residual of data is obtained.

Table 3. Analysis of variance table [Partial sum of squares - Type III]

\begin{tabular}{ccccccc}
\hline Source & $\begin{array}{c}\text { Sum of } \\
\text { Squares }\end{array}$ & Df & $\begin{array}{c}\text { Mean } \\
\text { Square }\end{array}$ & $\begin{array}{c}\text { F } \\
\text { Value }\end{array}$ & $\begin{array}{c}\text { p-value } \\
\text { Prob>F }\end{array}$ \\
\hline Model & 44.03 & 2 & 22.02 & 8.33 & 0.0074 & significant \\
A-sand & 37.84 & 1 & 37.84 & 14.32 & 0.0036 & \\
replacement & 6.19 & 1 & 6.19 & 2.34 & 0.1569 & significant \\
B-w/c & 26.42 & 10 & 2.64 & & $<0.0001$ \\
Residual & 26.33 & 6 & 4.39 & 196.98 & & \\
Lack of Fit & 0.089 & 4 & 0.022 & & & \\
Pure Error & 70.45 & 12 & & & & \\
Cor Total & & & & & & \\
\hline
\end{tabular}

From Table 4, the actual value, predicted value and residual is derived from the diagnostic case statistic. From these values, it can be seen that the values of standard order 3 and 5 is very high which influenced to the low values of Rsquared and Adj R-squared. However, from the analysis, it is known that these results were obtained due to the modification of particle size distribution, compressive index and consolidation index. These modification is more to physical performance of the bricks. Therefore, the repetition of this standard orders still give the same values. Therefore, it is concluded that the optimization of the bricks parameter cannot be done using this method.

Table 4. Diagnostic Case Statistic

\begin{tabular}{cccc}
\hline Standard Order & Actual Value & Predicted Value & Residual \\
\hline 1 & 7.57 & 6.60 & 0.97 \\
2 & 2.95 & 3.05 & -0.096 \\
3 & 11.64 & 8.03 & 3.61 \\
4 & 3.73 & 4.48 & -0.75 \\
5 & 6.07 & 9.09 & -3.02 \\
6 & 1.68 & 1.99 & -0.31 \\
7 & 3.68 & 4.10 & -0.42 \\
8 & 5.56 & 6.98 & -1.41 \\
9 & 5.80 & 5.54 & 0.26 \\
10 & 5.70 & 5.54 & 0.16 \\
11 & 5.70 & 5.54 & 0.16 \\
12 & 5.87 & 5.54 & 0.33 \\
13 & 6.06 & 5.54 & 0.52 \\
\hline
\end{tabular}

\section{Optimization of bricks using $w / c$ ratio}

The optimum sand replacement percentage was $25 \%$ RG. Therefore, this mix was selected to undergo optimization by varying the water to cement (w/c) ratio. Five (5) different w/c ratios were chosen which range from 0.35 to 0.55 . This range was selected based on the workability of the brick produced and the limitation of the machine used.

\section{Compressive strength}

Figure 3 shows the compressive strength of RG bricks with different w/c ratio at $25 \%$ replacement of sand. The result of compressive strength for $25 \%$ replacement of sand at $0.45 \mathrm{w} / \mathrm{c}$ ratio was considered. For comparison, the average compressive strength of conventional cement brick (CCB) tested was $10.9 \mathrm{MPa}$. 


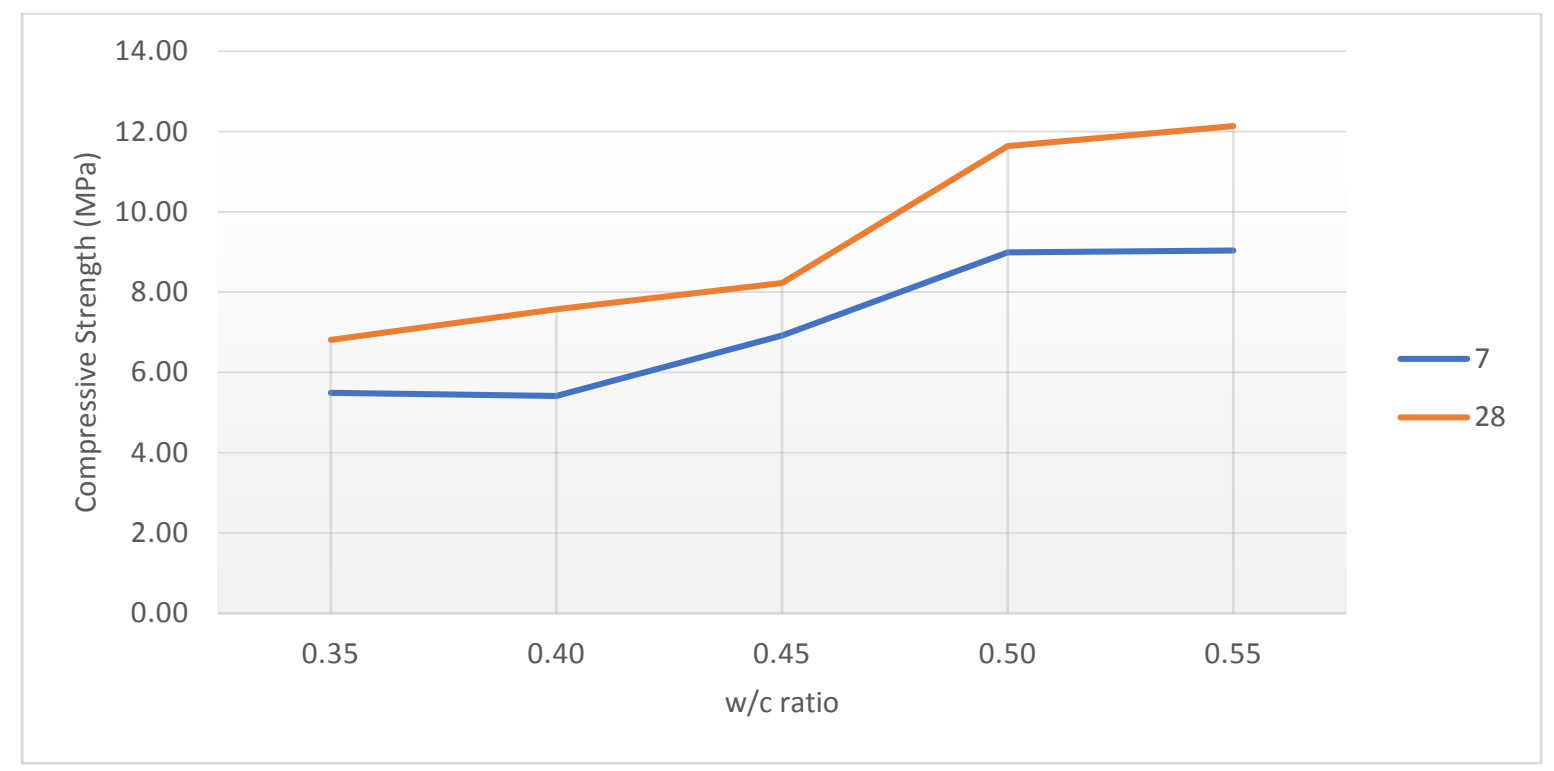

Figure 3. Compressive strength of RG brick with different w/c ratio

From Figure 3, it can be seen that the compressive strength of RG bricks with different w/c ratio increased progressively with the increasing w/c ratio. On the other hand, in general, the compressive strength increased in line with the duration of curing. From the findings, at 7 days, the bricks gain better early compressive strength with the increase of w/c ratio. The compressive strength obtained at $0.35 \mathrm{w} / \mathrm{c}$ is $5.49 \mathrm{MPa}$ and $5.41 \mathrm{MPa}$ at $0.40 \mathrm{w} / \mathrm{c}$ ratio. A quite similar value of compressive strength obtained for both w/c ratios may be due to less significant effect of water to produce uniformity of mix. However, the value of compressive strength shows a sudden rise to $6.91 \mathrm{MPa}$ at $0.45 \mathrm{w} / \mathrm{c}$ which further increases to $8.99 \mathrm{MPa}$ and then to $9.03 \mathrm{MPa}$ at 0.50 and $0.55 \mathrm{w} / \mathrm{c}$ respectively. An increase of about $65 \%$ in compressive strength value is revealed with the increase of w/c ratio. Similar trend can be seen for samples at 28 days of curing. At 28 days, the compressive strength of RG bricks increased from $6.81 \mathrm{MPa}$ at 0.35 to $7.57 \mathrm{MPa}$ at $0.40 \mathrm{w} / \mathrm{c}$ ratio. The value of compressive strength further increases to $8.23 \mathrm{MPa}, 11.64 \mathrm{MPa}$ and $12.14 \mathrm{MPa}$ at $0.45,0.50$ and $0.55 \mathrm{w} / \mathrm{c}$ ratio respectively. These values meet the threshold limit (5 MPa) set by the Malaysian Construction Standard, MS 72: 1976. Besides, the values of compressive strength obtained are higher compared to the average compressive strength of conventional cement bricks which was $10.9 \mathrm{MPa}$.

The effect of water in optimizing the compressive strength of RG bricks with $25 \%$ replacement were further evaluated in terms of rate of reaction, particle size distribution, physical characteristic of raw material and pore structure. One of the important factors for optimizing the hydration process is by evaluating the water requirement. In this study, the compressive strength of RG bricks shows a progressively increasing trend which may be attributed to sufficient amount of water being added into the mix for hydration process to occur. Hydration process of mortar starts when water is added to the mixture during casting of the bricks. During hydration process, calcium oxide $(\mathrm{CaO})$ in the mixture mainly from cement will react with water to produce an amorphous calcium silicate hydrate $(\mathrm{CSH})$ and calcium hydroxide $\left(\mathrm{Ca}(\mathrm{OH})_{2}\right)$. The hydration process continues with carbonation process where presence of outer carbon dioxide $\left(\mathrm{CO}_{2}\right)$ from the surface penetrates through the pores of the bricks. This would then react with the $\mathrm{Ca}(\mathrm{OH})_{2}$ inside the bricks to produce calcium carbonate $\left(\mathrm{CaCO}_{3}\right)$. In lieu of this, the increasing trend of compressive strength with increasing w/c ratio may be attributed to presence and volume of water added to the mixture. The increasing pattern of compressive strength from 0.35 to 0.55 shows that more water added to the mixture gives the opportunity for hydration process to occur. At $0.55 \mathrm{w} / \mathrm{c}$ ratio, the mixture consumes sufficient water needed to undergo hydration process. Sufficient amount of water during mixing process allows more $\mathrm{CaO}$ to react with water in order to produce the main products of hydration which are $\mathrm{CSH}$ and $\mathrm{Ca}(\mathrm{OH})_{2}$. At $0.35 \mathrm{w} / \mathrm{c}$ ratio, low amount of water might have decreased the tendency for $\mathrm{CaO}$ to undergo hydration process. At this low w/c ratio, less $\mathrm{CaO}$ reacts with water which then results in less production of $\mathrm{CSH}$ and $\mathrm{CaCO}_{3}$. In this case, the demand of water is also very critical as RG contains very fine particles with high surface area. Therefore, it can be concluded that more water is needed for the mix to attain proper homogeneity. However, the value of compressive strength also depends on the physical characteristics of raw material as the increment of w/c ratio has modified the physical properties of the raw material.

Physical characteristic of raw material includes compression index, consolidation index and hardness of material. As shown in Figure 3, introducing more water to the mixes increased the compressive strength of bricks. In this case, the particle size distribution cannot be taken into consideration as all the mixes were replaced by same amount of RG. However, it is confirmed that the chemical reaction is not involved in enhancing the durability of the bricks produced as discussed in 
previous section. Therefore, the physical performance of the bricks produced from varying the w/c ratio need to be evaluated. Table 5 shows the average thickness, weight and density of bricks with different w/c.

Table 5. Average thickness, weight and density of bricks with different w/c

\begin{tabular}{ccccc}
\hline No. & Mix & Average Thickness $(\mathrm{mm})$ & Weight $(\mathrm{kg})$ & Density $\left(\mathrm{kg} / \mathrm{m}^{3}\right)$ \\
\hline 1 & S0.35 & 78 & 3.110 & 1949 \\
2 & S0.40 & 76 & 3.111 & 1995 \\
3 & S0.45 & 73 & 3.070 & 2067 \\
4 & S0.50 & 74 & 3.010 & 1999 \\
5 & S0.55 & 73 & 3.120 & 2080 \\
\hline
\end{tabular}

The evaluation of the physical characteristic performance has been made by analysing the average thickness, weight and density of bricks. Based Table 3, it can be said that the average thickness of bricks reduced with the increase of w/c ratio. The variation of w/c also shows a significant influence on thickness where the highest average thickness of bricks achieved was 78 at S0.35 and the smallest was 73 at S045 and S0.55. The average thickness of S0.35 was at $78 \mathrm{~mm}$ before it dropped to $76 \mathrm{~mm}$ at S0.40. The value dropped to $73 \mathrm{~mm}$ at S0.45 before constant values were obtained regardless of further increase in w/c ratio. It can be concluded that the average thickness of bricks reduced with the increase of w/c ratio. On the other hand, the increase of w/c ratio increased the density of the brick from $1949 \mathrm{~kg} / \mathrm{m}^{3}$ to $2080 \mathrm{~kg} / \mathrm{m}^{3}$. The increase in density of bricks is smaller compared to the development of compressive strength obtained from varying the w/c ratio. However, the improvement of bricks through its thickness shows that the bricks are more compact when more water was added. In this case, the compactness level was influenced by level of w/c ratio and pressing capacity of machine as the particle size distribution of all samples were constant. Therefore, in determining the factors, the physical characteristic of raw material such as hardness, compression and consolidation index were evaluated.

Physical characteristic of sand and RG were important to be evaluated as the replacement was made using different characteristic raw materials. Sand was the main element of bricks which appears to have high hardness value as it is classified in quartz zone. The hardness value of sand was rated at 7 of Mohs hardness with an absolute hardness of 100 . $\mathrm{RG}$ was proposed in this study as the replacement material of sand and this material is known to be soft. RG was classified as gypsum-based material with level 2 of Mohs hardness with absolute hardness of 3 . The combination of sand and RG as raw material of bricks has altered the hardness values which give the opportunity for increasing the compactness level of the bricks. This statement is in accordance with the result of average thickness presented in Table 3. Alteration of physical characteristic of raw material has been shown to be dominant although the modification of particles size distribution helps in obtaining the maximum compactness level. The alteration of raw material used in bricks improved with the introduction of higher w/c where the compression and consolidation index of the mixes increased. However, all the factors including hardness, compression, and consolidation index of sand and RG were found dependant on the characteristic of RG itself.

In this section, the compressive strength of RG brick increased with the increase in w/c ratio where the replacement percentage of RG was constant. Previously, the discussion focuses on how the w/c ratio affects the hardness, compression and consolidation index of combination of sand and RG. However, the characteristic of RG was found to affect the physical performance of the bricks. The characteristic includes the particle size and water demand of RG. From the sieve analysis of RG, the particle size distribution of RG lies within the average particle size of RG which was calculated at 56.03 um. From the calculated average particle size, it is known that RG consists of very fine particles with high specific surface area. This physical characteristic of RG has significant effect on the value of w/c ratio used as it requires more water in order to increase the compressive strength of the brick. In previous section, addition of more water was assumed to be used in increasing the rate of reaction of the bricks produced. Another positive impact of adding more water to the mix was to increase the compaction capacity of the mix. Low w/c ratio results in dryness of the mix and lowering the compaction capacity of the mix. It can be seen from Table 3 that the high thickness of RG bricks was obtained using low w/c ratio. Besides, the high demand of water may also result from the high-water absorbing capacity of RG or perhaps due to the high surface area of this material. Therefore, it can be concluded that the use of RG in bricks would increase the water demand for compaction capacity purposes

\section{Water Absorption}

In this part, water absorption test was done in order to evaluate the effect of w/c ratio on the percentage of water absorption. For the record, there is no minimum requirement set by MS 76:1972 Specification for bricks and blocks of fired brickearth, clay or shale for water absorption. Figure 4 shows the water absorption results for $25 \%$ RG obtained with different $w / c$ ratios. 


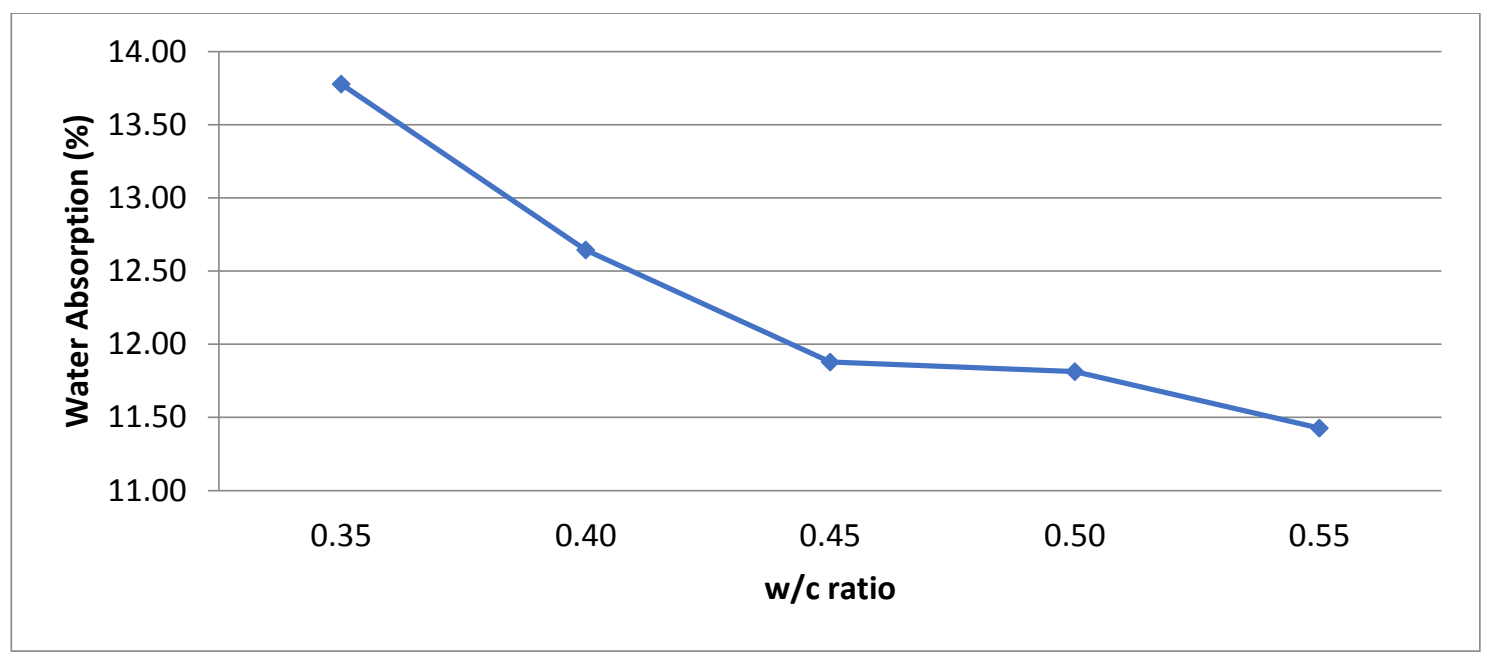

Figure 4. Water Absorption of $25 \% \mathrm{RG}$ with different w/c ratio

From Figure 4, it can be seen that the percentage of water absorption decreased with the increase in w/c ratio. The maximum water absorption percentage has been recorded at the minimum w/c ratio whereas the least water absorption percentage was at the maximum w/c ratio. The trend of water absorption can be seen to contradict with the compressive strength trend using the same w/c ratio. At $0.35 \mathrm{w} / \mathrm{c}$ ratio, the recorded water absorption percentage is $13.78 \%$ which decreased to $12.64 \%$ at $0.40 \mathrm{w} / \mathrm{c}$ ratio. The values for $0.45,0.50$ and $0.55 \mathrm{w} / \mathrm{c}$ ratios then further declined to $11.88 \%$, $11.81 \%$ and $11.43 \%$ respectively. However, it seems as if the variation of the percentage of water absorption is not very significant as only $2.35 \%$ difference is observed between the minimum and the maximum values of the water absorption percentage. In this case, the variation of w/c ratio had been seen to impact the compactness level of the mix. This is supported by the thickness and porosity values of the bricks produced. From Table 3, it can be seen that the thickness of the bricks produced decreased with the increase in w/c ratio. The relationship between thickness and the values of water absorption percentage can be discussed as the percentage replacement of sand by RG was constant. It can be seen that the increment of water absorption percentage was parallel to the thickness obtained. Higher thickness of bricks had caused the water absorption percentage to increase. At 0.35 , the water absorption percentage was $13.78 \%$ whereas $12.64 \%$ water absorption percentage was obtained at 0.40 . The values of water absorption tend to reduce with the increase in w/c ratio such that $11.88 \%, 11.81 \%$ and $11.43 \%$ were obtained at $w / c$ ratios of $0.45,0.50$ and 0.55 respectively. Based on this, it can be concluded that low thickness bricks can be produced with higher water to cement ratio. However, the water absorption values can also depend on the compressive strength and porosity of the bricks.

In this case, it can be seen that the compressive strength of the bricks increased with the increase in w/c ratio. It can be seen that higher compressive strength gave lower value of water absorption. The compaction during casting procedure seems to be large with respect to the thickness of the bricks produced with higher w/c ratio. A maximum compaction level had made the bricks to be less porous considering the thickness obtained. A good compaction during casting procedure reduced the brick's pores which in turn reduced the amount of water absorbed by the brick. In order to validate this data, a UPV test was done on each mix. Table 6 shows an increasing trend of UPV values with the increase in w/c ratio.

Table 6. UPV Value of bricks with different w/c ratio

\begin{tabular}{ccc}
\hline No. & w/c ratio & UPV Value $(\mathrm{m} / \mathrm{s})$ \\
\hline 1 & 0.35 & 2177.33 \\
2 & 0.40 & 2290.67 \\
3 & 0.45 & 2455.50 \\
4 & 0.50 & 2562.00 \\
5 & 0.55 & 2781.25 \\
\hline
\end{tabular}

From the UPV values, it is observed that more pores were generated at $0.35 \mathrm{w} / \mathrm{c}$ ratio than $0.55 \mathrm{w} / \mathrm{c}$ ratio. The higher speed of UPV indicates that the bricks are denser. Denser bricks with fewer pores prevent large amount of water from entering the bricks thereby reducing the percentage of water absorption.

\section{Industrial analysis on usage of RG as raw material}

One main focus of this study is on utilization of RG as sand replacing material in conventional cement bricks. There are two major factors, namely raw material and w/c ratio, were taken into account in order to ensure that an optimum 
operation result is obtained. For these purposes, mix with $25 \%$ replacement of sand by RG was chosen based on the analysis and discussion made from previous sections. The subsequent subsections focus on the operation of the brick plant which is more to the process of casting the conventional cement brick using an industrial approach.

\section{Raw Material}

Conventional cement bricks are normally made from cement, sand and water. From the analysis and discussion made in previous sections, RG is found to be a good sand replacement material rather than being used as cement replacement material. However, there are several other factors which need to be taken into considerations prior to possible commercialization of bricks with RG as sand replacement material such as availability of RG, practicality aspect, and most importantly, consideration of cost.

\section{Availability}

In Malaysia, waste RG is generated by more than five manufacturing plants, with an estimated total of more than one million tonnes a year. All of the waste RG is classified as scheduled waste. One particular industry (manufacturing titanium dioxide), situated within $80 \mathrm{~km}$ from Universiti Malaysia Pahang, produces approximately 340,000 tonnes of RG per annum. Presently, almost all of this waste is been dumped at landfills within the premise as this waste is classified as scheduled waste. A commercial brick plant usually produces an average of about 40,000 to 50,000 bricks per day. Based on the calculation made using mix design of S25, in a maximum production scale, and with the assumption that RG was used in replacing sand by $25 \%$, the reduction of the waste is estimated at 12,000 tonnes per annum. From the calculation, it is estimated that the waste generated from the titanium dioxide plant alone can be distributed to at least 25 brick plants with the same production capacity. Therefore, it can be concluded that there is great potential for the use of RG as sand replacement material.

\section{Practicality}

In looking at the practicality in terms of logistic and handling, the first factor is the consideration of location of the brick plant to be set up. In order to make it more practical in term of cost of transportation and handling, it becomes more logical for the the brick plant to be constructed close to the source of RG. This is to reduce the cost of transporting RG to the bricks plant. Nevertheless, the cost of transporting the RG can be absorbed since the material is free and there is savings from reduction of sand usage ( $25 \%$ sand replacement by RG). Besides, RG is lighter compared to sand. RG is also a compressible material as it is a soft material classified as gypsum with Mohs scale at level 2 with an absolute hardness of 3. Therefore, it is more flexible for this waste material to be handled during transportation.

\section{Costing}

As mentioned in the previous section, $\mathrm{RG}$ is a waste material with otherwise no notable commercial value. Therefore, it becomes more interesting to know that using RG as a sand replacement material would inevitably reduce the cost of raw material. In this study, it has been proven that replacing sand by $25 \%$ could improve the physical performance of the bricks without presenting significant negative effect on the chemical performance of the bricks. In an industrial setup, if the replacement can be made, the cost of raw material can be reduced to $10 \%$. For a large scale bricks plant, with production of bricks of up to 50,000 bricks a day, the calculation on the possible savings in cost is presented in Table 7 . 
Table 7. Cost illustration with respect to use of RG as replacement material

\begin{tabular}{|c|c|c|c|c|c|c|}
\hline \multirow[t]{2}{*}{ Material } & \multicolumn{3}{|c|}{ Without Replacement } & \multicolumn{3}{|c|}{ With Replacement } \\
\hline & $\begin{array}{l}\text { Weight } \\
(\mathrm{kg})\end{array}$ & $\begin{array}{l}\text { Unit Cost } \\
(\mathrm{RM})\end{array}$ & $\begin{array}{l}\text { Cost } \\
(\mathrm{RM})\end{array}$ & $\begin{array}{l}\text { Weight } \\
(\mathrm{kg})\end{array}$ & $\begin{array}{l}\text { Unit Cost } \\
(\mathrm{RM})\end{array}$ & $\begin{array}{l}\text { Cost } \\
(\mathrm{RM})\end{array}$ \\
\hline Cement & 10 & $0.40 / \mathrm{kg}$ & 4.00 & 10 & $0.40 / \mathrm{kg}$ & 4.00 \\
\hline Sand & 90 & $0.01 / \mathrm{kg}$ & 0.90 & 67.5 & $0.01 / \mathrm{kg}$ & 0.68 \\
\hline RG & - & - & - & 22.5 & & \\
\hline \multirow[t]{2}{*}{ Total } & \multirow{2}{*}{\multicolumn{3}{|c|}{$\begin{array}{c}\text { Unit Weight Brick }=3.60 \mathrm{~kg} \\
\text { Total Produced }=27 \text { unit } \\
\text { Unit Cost }=\text { RM } 0.18\end{array}$}} & & & 4.68 \\
\hline & & & & \multicolumn{3}{|c|}{$\begin{array}{c}\text { Unit Weight Brick }=3.10 \mathrm{~kg} \\
\text { Total Produced = } 32 \text { unit } \\
\text { Unit Cost = RM } 0.14\end{array}$} \\
\hline
\end{tabular}

Based on Table 7, the unit cost of the brick without replacement is RM0.18 while the bricks with replacement of RG cost about RM0.14. From the calculation, it can be seen that the cost of RG was not stated based on the assumption that the RG brick plant is situated close to the titanium dioxide plant. The reduction of cost with replacement of RG by sand was up to $22 \%$. However, the reduction is not only based on the ignored cost of RG, it is also related to the unit weight of the brick which is lesser compared to the conventional bricks. The reduction of unit weight of the brick is due to the increased compactness level during casting processes. The characteristic of RG helps in increasing the amount of bricks produced in a single batch. Therefore, from the cost analysis, it is obvious that the use of RG in brick plant manufacturing is feasible with potential positive impacts especially with respect to the economy and environment.

\section{CONCLUSION}

The red gypsum (RG) was used successfully to fabricate bricks using sand and cement. The purpose of using RG was to replace the cement and sand partially or eventually completely. Several ratio of water/cement was applied in fabricating the bricks. These parameters were considered as the factors whereas compressive strength and water absorption were considered as the factors or response of the analysis. It was observed that the compressive strength of RG brick increased with the increase in w/c ratio where the replacement percentage of RG was constant. In terms of waster absorption, it can be seen that the increment of water absorption percentage was parallel to the thickness obtained. In addition, it was observed that more pores were generated at $0.35 \mathrm{w} / \mathrm{c}$ ratio than $0.55 \mathrm{w} / \mathrm{c}$ ratio.

\section{REFERENCES}

1. Rose Aini Kamarudin and Mohd. Shahir Zakaria, the utilization of red gypsum waste for glazes, The Malaysian Journal of Analytical Sciences, 2007, 11(1) 57-64

2. Nurhidayah Binti Mahazam, Nurul Syafiqah Binti Mohd Azmi, Evaluation of Physical and Chemical Properties of Red Gypsum from Terengganu, Malaysia, International Journal of Engineering Research \& Technology, 2016, 5(1) 433-436.

3. Mohd Amirul Hakim Sidek, Rosli M. Yunus, Fadzil Mat Yahaya, Muhammad Faisal Baderolhissam, Mohamad AlNizar Khan Ahmad Khan, Properties of Mortar with Red Gypsum as Cement Replacement Material by Using Industrial Approach Method, Australian Journal of Basic and Applied Sciences, 2017, 11(13), 115-121.

4. Sophia M, Sakthieswaran N, Ganesh Babu O, Gypsum as a Construction Material- A Review of Recent Developments, International Journal for Innovative Research in Science \& Technology, 2016, 2(12), 315-323.

5. P. N. Hughes, S. Glendinning, D.A.C. Manning, B. C. Noble, Production of green concrete using red gypsum and waste, Engineering Sustainability, 2010, 163(3):137-146.

6. Gazquez, M. J., Bolivar, J. P., Vaca, F., García-Tenorio, R., \& Caparros, A. Evaluation of the use of TiO2 industry red gypsum waste in cement production. Cement and Concrete Composites, 2013, 37(1), 76-81.

7. Takanori Fukami, Shuta Tahara, Keiko Nakasone, Chitoshi Yasuda, Synthesis, Crystal Structure, and Thermal Properties of $\mathrm{CaSO} 4 \cdot 2 \mathrm{H}_{2} \mathrm{O}$ Single Crystals, International Journal of Chemistry, 2015, 7(2) 12-20.

8. Z. M. Razi, M. R. Islam, and Muvinkumar Parimalam, Mechanical, structural, thermal and morphological properties of a protein (fish scale)-based bisphenol-A composites. Polymer Testing, 2019, 1-21.

9. M. R. Islam, M.D.H. Beg, A. Gupta and M. F. Mina. Optimal performances of Ultrasound Treated Kenaf Fibre Reinforced Recycled Polypropylene Composites as Demonstrated by Response Surface Method. Journal of Applied Polymer Science, 2013, 128(5), 2847-2856. 